\title{
A volta da violência na política alemã. Estratégias legitimadoras na autobiografia de uma protagonista dos anos 1970
}

\author{
Helmut Galle ${ }^{1}$
}

Die Menschen, die jene Mittel gegen andere Menschen anwenden, sehen sich gezwungen, diese anderen Menschen, d.h. ihre Opfer und Objekte, auch moralisch zu vernichten. Sie müssen die Gegenseite als Ganzes für verbrecherisch und unmenschlich erklären, für einen totalen Unwert. Sonst sind sie eben selber Verbrecher und Unmenschen.

Carl Schmitt, Theorie des Partisanen

Das Selbstbewußtsein ist an und für sich, indem und dadurch, daß es für ein Anderes an und für sich ist; $d$. h. es ist nur als ein Anerkanntes.

Hegel: Phänomenologie des Geistes

\begin{abstract}
Among the different functions that an autobiography might have is the claim for recognition. Some of the former members of the militant German Left from the Seventies have published autobiographical texts in the latest years. In the analysis of Inge Viett's book, the author raises the question of responsibility for her violent aiming at reaching her readers' recognition.
\end{abstract}

Keywords: Autobiography; Terrorism; Red Army Faction; Recognition; Violence

Resumo: Entre as diferentes funções que uma autobiografia pode assumir está a reivindicação de reconhecimento. Vários dos integrantes da esquerda militante alemã dos anos 1970, que romperam radicalmente com a sociedade, publicaram, nos últimos anos, textos autobiográficos. Na presente análise do livro de Inge Viett, a autora discute a questão da responsabilidade de seus atos violentos com o propósito de alcançar o reconhecimento de seus leitores.

Palavras chave: Autobiografia; Terrorismo; Rote Armee Fraktion; Reconhecimento; Violência

Zusammenfassung: Zu den diversen Funktionen, die einer Autobiografie zufallen können, gehört das Streben nach Anerkennung. Einige der früheren Mitglieder der militanten deutschen Linken der 70er Jahre haben in den vergangenen Jahren autobiografische Texte veröffentlicht. Die folgende Analyse folgt der Fragestellung, auf welche Weise die Autorin ihre Verantwortung für die Gewaltakte und ihre Forderung nach Anerkennung formuliert

Stichwörter: Autobiografie; Terrorismus; Rote Armee Fraktion; Anerkennung; Gewalt

\footnotetext{
${ }^{1}$ Professor doutor do Departamento de Letras Modernas, Universidade de São Paulo. Endereço eletrônico: hgalle@usp.br
} 


\section{Autobiografia como reivindicação de reconhecimento}

Inge Viett começa sua autobiografia Nie war ich furchtloser (Nunca fui mais intrépida. 1996; traduções do autor) relatando a promulgação da sentença de 13 anos de prisão: em 1992, um tribunal da República Federal julgou-a culpada de tentativa de homicídio. No público presente, um grupo de simpatizantes manifestou seu repúdio pela condenação, em solidariedade aos "prisioneiros políticos”, insinuando a continuação de uma luta violenta, da qual Viett tinha participado como ativista militante nos anos 1970, para depois refugiar-se na antiga RDA. Aí viveu sob identidade falsa e levou uma vida “normal” no estado socialista alemão. Ser descoberta após a unificação e aceitar a sentença (que poderia ter sido mais grave, como observa a própria autora) significou, por outro lado, uma nova etapa em sua vida. Terminaram os anos da ilegalidade nos quais a opção pela luta armada contra o estado erigiu uma clara fronteira entre si e o resto da sociedade. Uma vez cumprida sua pena, ela teria novamente a liberdade de continuar sua vida como cidadã normal entre tantos, mesmo que optasse por uma atitude política de esquerda; tal fato aconteceu um ano após a publicação do livro, em 1997, quando a segunda metade da pena foi suspensa com a aplicação de liberdade condicional.

Aceitar a pena não significa assumir a culpa. A autobiografia de Viett não deixa dúvida quanto ao fato de que a condenada somente acata o poder do estado por considerá-lo superior à sua própria força. A luta violenta ainda lhe parecia justificada; a detenção seria somente a última ação do inimigo para aniquilar sua resistência. Em vez da luta armada, a defesa consistia, agora, na redação da sua autobiografia. Para ela, contar sua vida é “parte de uma estratégia para sobreviver” (VIETT 1996: 7), nas condições da prisão, e "manter vivo o passado" (ibid. 9), numa época na qual triunfa a “inquebrantável aspiração pelo poder mundial” da Alemanha (ibid. 7).

Viett encontra-se, politicamente, no limite da extrema esquerda, mas ainda dentro das margens de tolerância da democracia alemã. O que interessa no livro dela, porém, não são os distorcidos comentários políticos, mas a forma como representa sua própria vida. Seu empreendimento na escritura autobiográfica não é somente uma atividade para sustentar o vazio e a hostilidade do cárcere. Voltando a uma vida legal, a autora submete sua biografia e sua versão dos fatos ao juízo público. Contra a história de criminosa e a identidade de culpada que a sociedade lhe impõe, ela reivindica uma outra história que inverte a lógica: culpados são a sociedade e o estado. O livro é, 
portanto, uma tentativa de justificar a luta da guerrilha armada em geral e as ações violentas da autora em particular.

Narrando sua vida, um autor representa suas ações, intenções e consequências, de acordo com sua memória e interpretação subjetiva. Muitas vezes - particularmente quando a vida do autor está em conflito com as normas da religião ou da sociedade -, a autobiografia é uma confissão: a vida se separa em duas fases, uma primeira vida errada ou pecaminosa e, após uma conversão, a nova vida que é considerada a verdadeira. ${ }^{2} \mathrm{O}$ ato comunicativo do autobiógrafo, dirigindo-se a Deus ou aos homens, requer que atos passados e atitudes presentes frente a eles sejam examinados e, se possível, sejam reconhecidos como justificáveis. Com certeza, Viett não escreveu uma confissão. Sua autobiografia segue, a bem dizer, o modelo de Goethe, que teve aversão a remorsos e quis delinear sua vida como um processo orgânico. Viett não está arrependida e sua vida não apresenta nenhuma verdadeira conversão, com exceção da renúncia prática à luta armada. Essa, porém, não se deve a uma mudança de convicção política, mas a uma reavaliação de suas próprias forças.

O fato de publicar sua autobiografia pode ser entendido como um apelo ao diálogo, um ato comunicativo que exige da sociedade, com a qual entra novamente em relações pacíficas, que a reconheça como ser humano. Esse reconhecimento ${ }^{3}$ refere-se, em especial, às ações que causaram sua exclusão: a violência contra seres humanos. Juridicamente, ao cumprir a pena, ela alcança, novamente, o estatuto da cidadania completa: frente à lei, é reconhecida como sujeito inocente. Frente à sociedade, porém, ela ainda é considerada autora de atos que romperam o contrato do reconhecimento mútuo. Para ela, isso deve ser muito mais incômodo do que para “criminosos normais”, pois mantém uma imagem de si que a representa como idealista e lutadora pela felicidade dos homens. Por consequência, precisa provar sua integridade e coerência exatamente nas ações que afetam a integridade física e a felicidade de outras pessoas. Nessas ações, a luta contra o poder abstrato do estado converte-se em atos que, na

\footnotetext{
${ }^{2}$ Starobinski constata que um motivo necessário para uma autobiografia consiste na "mudança fundamental da vida anterior: uma conversão, a entrada em uma nova vida, a irrupção da graça”. (STAROBINSKI 1998: 207)

${ }^{3}$ O conceito "reconhecimento" (Anerkennung) como base da autoconsciência é introduzido no $4^{\circ}$ capítulo da Fenomenologia do Espírito. O conceito foi retomado por Axel Honneth (2003) para formular uma teoria geral das relações sociais a partir da "luta por reconhecimento". No seu último livro, Paul Ricoeur (2006) esboça um "caminho filosófico" da reconnaissance desde o ato da "identificação", passando pelo reconhecimento da responsabilidade pelos próprios atos para o reconhecimento mútuo e a utopia da reconciliação pacífica.
} 
realidade, negam o direito de ser de determinados homens, sejam eles policiais, políticos, seus motoristas ou vítimas arbitrárias. Os atos violentos rompem com o reconhecimento mútuo que é a base da convivência civilizada. A reciprocidade dessas relações demanda que a autora reconheça - pelo menos retrospectivamente - o direito de ser de suas vítimas -, e isso implica, de alguma forma, o remorso ou a revisão de posições anteriores. Por isso, a autobiografia deve, além de tentar legitimar a luta armada, apresentar o reconhecimento dos próprios atos como atos responsáveis, e as vítimas dos atos como seres humanos com direito à integridade física.

No que segue, esboço, em primeiro lugar, o contexto histórico da vida de Viett, para depois analisar as estratégias discursivas através das quais a autora reconstrói a continuidade de sua vida e de sua identidade, a maneira pela qual ela legitima a luta armada e de que forma se relaciona com a responsabilidade por seus atos violentos.

\section{O contexto histórico do terrorismo ${ }^{4}$}

A fase entre 1968 e 1977 pode ser considerada como a de maior crise interna na sociedade alemã desde o fim da guerra. Durante os anos 1960, a nova geração havia se revoltado contra os pais, contra o estado e seu passado, a aliança ocidental e a guerra do Vietnã. Em consonância com a juventude rebelde da maioria dos países europeus e americanos, essa oposição “revolucionária” limitou-se ao âmbito universitário e não conseguiu convencer os trabalhadores - o principal alvo de sua agitação - a participarem dessa luta, a qual, por conseguinte, entrou em estagnação a partir de 1970. Ao discordar sobre a estratégia mais adequada, uma parte da juventude rebelde deu início à “marcha pelas instituições”, resultando, anos mais tarde, na criação do partido verde. Outro grupo fundou uma série de micropartidos marxistas; e um terceiro grupo decidiu radicalizar-se e combater o estado de forma armada. Embora o núcleo ativo dos grupos desafiantes do poder alemão nunca tenha superado um total de 100 pessoas, esse núcleo consegue polarizar a sociedade de maneira inaudita, resultando em uma espiral de posições cada vez mais intransigentes e de ações cada vez mais duras. Em 1977, a confrontação culminou no sequestro do magnata industrial Martin Schleyer e de um avião de turistas alemães, numa tentativa desesperada de forçar a libertação dos líderes da RAF (“Facção Exército Vermelho”) que se encontravam há cinco anos encarcerados

\footnotetext{
${ }^{4}$ O resumo baseia-se, em primeiro lugar, no livro de Aust (1989); reconstruções mais abrangentes e mais atuais apresentam: Peters (2004), Koenen (2005) e Kraushaar (2006).
} 
em prisões de alta segurança. O governo social-democrata (aconselhado por um estadomaior de emergência que incluía o partido conservador, então na oposição) não aceitou libertar os prisioneiros e 'garantiu' a liberdade dos passageiros do avião da Lufthansa por meio de uma arriscada operação militar relâmpago. Como resultado da operação, os três líderes presos se suicidaram (ou, segundo a versão da RAF, foram massacrados) e os sequestradores executaram o magnata. Um retrato do racha que dividiu a sociedade alemã naquele momento é o filme do novo cinema alemão Deutschland im Herbst (1978); o filme reúne os trabalhos de onze diretores em suas tentativas de lidar com a impossibilidade de encontrar uma posição própria e viável entre o terrorismo radicalizado e a atitude irreconciliável do estado e da maior parte da sociedade. Ainda que a RAF tenha declarado sua dissolução em 1998, após anos de novos assassinatos (desde a formação do grupo, foram cometidos um total de 34 homicídios), o assunto não chegou a um término: um grande número de terroristas, libertado após cumprir longas penas de prisão (de 20 anos e mais), reclamou que sua luta foi justa, seus motivos nobres e as vítimas necessárias. Por não terem colaborado com os órgãos judiciários em depoimentos e confissões, os culpados de vários assassinatos não foram identificados, mesmo que os autores imputados tenham sido punidos de forma sumária e coletiva. Nesse sentido, nenhuma das partes envolvidas (o estado, os ex-terroristas e os familiares das vítimas) considerou que houve uma verdadeira "justiça” e que algum tipo de reconciliação ou paz pôde ser estabelecido. Para a geração de 1968, que passou a desempenhar papeis de destaque em quase todos os setores da sociedade ao longo dos últimos 40 anos, sua trajetória é, em retrospectiva, contraditória: por um lado, inconsequente, oportunista e covarde e, por outro, adequada tanto aos princípios éticos básicos e à situação real daqueles anos. Para muitos integrantes dessa geração, à qual eu me incluo, o fato de não ter participado da "luta armada” e não ter perdido a vida em combate ou na prisão, não é resultado de uma escolha consciente e responsável, mas produto da interação de muitos fatores externos e internos, que, vistos da perspectiva de hoje, podem ser descritos como “felizes”. Para nós, que escapamos apenas com o simples susto, os ex-terroristas têm quase a função de bodes expiatórios que se sacrificaram aceitando não somente a responsabilidade por um comportamento mais fiel a si mesmo, mas também o castigo da sociedade. ${ }^{5}$

\footnotetext{
${ }^{5}$ Sobre esse aspecto cf. Theweleit 1998.
} 
Inge Viett foi uma protagonista do "Movimento 2 de Junho", uma outra organização militante, menos numerosa, menos hierárquica e rigorosa, cujos últimos integrantes finalmente se alistaram na RAF em 1980. Nascida em 1944 e criada por pais adotivos (com certeza, uma infância dura e precária, mas não típica dos protagonistas do terrorismo), ela teve empregos temporários antes de chegar a Berlim no fim dos anos 60. Logo aderiu às estruturas informais da rebelião e foi um dos membros fundadores do "Movimento 2 de Junho”, em 1971/72. Foi presa, escapou da prisão duas vezes através de fugas quase cinematográficas, participou do sequestro de um político conservador em 1975 - uma das poucas operações desse tipo que teve êxito e resultou na libertação de prisioneiros -, deixou um policial paralítico num tiroteio em Paris em 1981, viveu na RDA com uma identidade falsa e com ajuda da Stasi ${ }^{6}$ de 1982 até a unificação em 1990, quando foi descoberta, presa e sentenciada por um tribunal da Alemanha Federal. Desde a suspensão do resto da pena, em 1997, publicou quatro livros, dentre os quais a autobiografia, escrita no cárcere, teve o maior sucesso e foi utilizada na elaboração do roteiro do filme Die Stille nach dem Schuss, de Volker Schlöndorff. Ela, até hoje, não se distanciou da sua vida pregressa, continua defendendo o sistema da RDA e considera legítima a luta contra o capitalismo e o imperialismo.

\section{A autobiografia de Viett}

O livro Nie war ich furchtloser. Autobiographie foi publicado por uma pequena editora de esquerda. ${ }^{7} \mathrm{O}$ volume contém, além do texto da autobiografia, algumas fotos da autora, um prólogo e um epílogo. Nessa moldura, a autora articula sua posição política no momento da enunciação. Um glossário dá explicações sobre acontecimentos históricos, pessoas e instituições, ressaltando, assim, o caráter factual do livro.

Viett considera que o terrorismo alemão foi tão necessário e legítimo como qualquer outra forma de resistência contra "a hegemonia conservadora e chauvinista existente ao longo dos séculos” (“die konservative und chauvinistische Herrschaft durch die Jahrhunderte”), contra “o militarismo, fanatismo racial, duas guerras mundiais, a

\footnotetext{
${ }^{6}$ Vale mencionar, que as ideias sobre o socialismo da esquerda estudantil ocidental e da sua vertente militante divergiram fortemente do programa do SED, partido ditatorial da RDA, ainda que Viett,no seu livro, pretenda que os objetivos convirjam grosso modo. O apoio da Stasi aos terroristas se deve menos a uma convergência de ideais sociais da RDA e da RAF, e mais ao interesse geral da Stasi de desestabilizar os estados democráticos ocidentais.

${ }^{7}$ O catálogo da Edition Nautilus abrange livros policiais e títulos de Noam Chomsky, Raoul Vaneigem, Otto Gross, Victor Serge, Jacques Mesrines e diversos ex-terroristas.
} 
eliminação da RDA e a ambição continuada pelo poder mundial” (“Militarismus, Rassenwahn, zwei Weltkriege, die Eliminierung der DDR und das ungebrochene Streben nach Weltmacht”; VIETT 1996: 7). Ter participado de uma insurreição contra “a realidade capitalista, destrutiva e sem futuro" (“die destruktive und zukunftslose kapitalistische Realität”; 8) dá-lhe o direito de falar sobre essa insurreição, no tempo atual, “da forma como eu, naquele tempo, pensava e sentia a respeito” (“in der Weise zu reden, wie ich in der damaligen Zeit darüber gedacht und gefühlt habe”; 8). Por um lado, ela escreve que sua história possui "seus motivos e sua legitimação nos acontecimentos da recente história sociopolítica” ("seine Gründe und seine Berechtigung im politisch-sozialen Zeitgeschehen”; 8); por outro lado, "é a expressão de uma subjetividade selvagem” (“Ausdruck wilder Subjektivität”; 8).

Além disso, escrever a autobiografia seria um ato de resistência e defesa contra a “violência burocrática”: “Escrevo para manter-me viva atrás dos muros.” („Ich schreibe, um hinter Mauern lebendig zu bleiben.“ 9) Nota-se que, de maneira geral, a linguagem é utilizada de forma metafórica: “violência” para a ordem penitenciária, “manter-se vivo” para a proteção da identidade, “expressão de subjetividade” para atos criminosos e violentos etc. Daí resulta uma inexatidão que oculta exageros e distorções.

As afirmações sobre a RFA e o capitalismo, em especial, misturam de forma grosseira o processo da unificação alemã com os processos jurídicos contra os terroristas, o consumismo com as guerras (do Golfo, na Iugoslávia), em suma: um “desencadeamento da barbárie no Oriente e no Ocidente” (308).

\begin{abstract}
Os conquistadores armados deixam atrás vestígios negros, quando passam por um país conquistado: aldeias queimadas, cidades bombardeadas, homens violados. Os vencedores da Guerra Fria devastaram o passado e o futuro dos homens, prenderam-nos num presente cheio de medo sem retrospecto e perspectiva e atiraram-nos na miséria filosófica. (308) ${ }^{8}$
\end{abstract}

Esse ,diagnóstico’ da civilização europeia-americana após o fracasso da União Soviética mostra a extrema distorção do olhar da autora, que utiliza as fórmulas trilhadas da propaganda de maneira desajeitada para atribuir todos os problemas do mundo e seu próprio destino a uma só causa. O termo “abwickeln” (efetuar / executar /

8 „Die Eroberer in Waffen hinterlassen schwarze Spuren, wenn sie erobertes Land durchziehen: verbrannte Dörfer, zerbombte Städte, geschändete Menschen. Die Sieger des kalten Krieges verheerten die Vergangenheit und die Zukunft der Menschen, sperrten sie ohne sinnvollen Rück- und Ausblick in die angstvolle Gegenwart und stießen sie ins philosophische Elend. “ (308) 
liquidar), usado inicialmente para designar o processo técnico de transformar as instituições socialistas em democráticas, depois um termo irônico da crítica contra a suposta ou verdadeira - destruição das estruturas, é usado pela autora para sugerir que seu processo jurídico foi manipulado pelo estado "para liquidar a história da guerrilha urbana de forma jurídica e denunciadora” (“die Geschichte der Stadtguerilla juristisch und denunziatorisch abzuwickeln”; 309), insinuando dessa maneira que as ações do estado de direito foram um processo destrutivo e injusto que igualmente destruiu duas políticas socialistas que aliás, na realidade histórica, mantiveram-se em considerável distância. Trata-se de estratégias retóricas que vinculam o destino da própria autora e sua posição extremamente minoritária - tanto na RFA como na RDA - com a crescente crítica - seja essa justificada ou não - ao processo da unificação.

Nem vale aqui a pena e nem é este o lugar para analisar as manifestações políticas da autora de forma argumentativa. Basta constatar que elas se encontram em total coerência com o mundo descrito na própria autobiografia. Na aldeia onde Viett foi criada, os campesinos cumprimentavam-se - nos anos 50! - com “Heil Hitler!” (32), os pais de criação - cujos nomes nunca são mencionados - aproximam-se a figuras de conto de fadas, no qual a madrasta bruxa atormenta e explora a pequena protagonista. É esse mundo completamente hostil e adverso que impele os jovens para a radicalidade, “a frieza social de uma geração de guerra desalmada que negou ou suprimiu seus incomparáveis crimes” (“die soziale Kälte einer herzlosen Kriegsgeneration, die ihre beispiellosen Verbrechen leugnete oder verdrängte”; 18). Na escola autoritária, a protagonista declara ter protegido a 'irmã' mais fraca por meio de golpes e de uma superioridade intelectual contra a discriminação de parte dos alunos e docentes (37). Aos 14 anos, conhece o amor na forma de uma paixão inocente por uma professora de ginástica (41), compensação pelo estupro de que foi vítima nas mãos de um campesino (44). Em resumo, constata que durante a infância "não experimentou nada espetacular ou traumático como milhões de outras crianças” (51). Mesmo assim, foi um esforço suportar "as inevitáveis humilhações diárias [...], a somatória de rudeza e desprezo, a arbitrária disposição alheia sobre corpo e alma, o embrutecimento impudico” (“die Unausweichlichkeit täglicher Erniedrigungen [...] die Zusammenballung von Lieblosigkeit und Mißachtung, der beliebige fremde Zugriff auf meinen Körper und meine Seele, die schamlose Verrohung"; 51). 
A protagonista radicaliza-se junto com a maioria dos estudantes nas manifestações de 1968 e 69, decidindo-se, no início de 1972, a usar armas de fogo e viver na ilegalidade. A decisão de aderir ao "Movimento 2 de Junho" (a data do assassinato de estudante Benno Ohnesorg por um policial) é compartilhada já por poucos, uma dúzia de amigos que se consideram uma elite formada pelos mais corajosos e coerentes. ${ }^{9}$ A ideia é que “as massas” os sigam tão logo seu exemplo seja bem-sucedido. O grupo realiza uma série de ações mais ou menos exitosas - roubos, atentados a bomba, assassinatos, sequestros, fugas de prisão etc., mas paulatinamente registram-se também a diminuição e o isolamento do grupo ativo, a erosão do ambiente entre os simpatizantes e a crescente pressão do aparato de segurança do estado.

Cabe mencionar que, no fim dos anos 60, a visão de mundo de vários jovens rebeldes não era menos simplista que esses temas maniqueístas, lembrados e repisados pela autora. Contudo, todos os exageros diziam respeito, no final das contas, a defeitos inegáveis da sociedade alemã e à culpa histórica. A evolução da guerra do Vietnã e a sobrevivência de ditaduras na Europa e no restante do mundo preocupavam também observadores de maior experiência e, para um adolescente impaciente, tudo isso podia resultar na decisão de combater de forma militante “o sistema” que parecia ser o responsável por todos os males (cf. 78 ss.). Uma vez declarada a guerra, esses guerrilheiros urbanos entraram num circuito vicioso: Definindo-se como inimigos do estado (e da maioria dos seus leais cidadãos), eles foram necessariamente tratados como inimigos, afirmando assim a 'verdade' do seu pressuposto. O confronto se brutaliza cada vez mais porque a pequena dimensão do grupo não permite outra alternativa que a prática de ações violentas feitas de surpresa. E o estado não tem outra opção que mobilizar todos os meios para garantir seu monopólio da violência e a segurança pública.

A experiência do século XX sancionou juridicamente a legitimidade da guerrilha contra invasores e regimes totalitários. A teoria da guerrilha, que remete a Clausewitz, Lenin e Mao Tse Tung, distancia-se da guerra convencional entre estados para ser uma intervenção limitada com meios e fins limitados. Na sua Theorie des Partisanen, de 1964, Carl Schmitt esboça como as ações armadas na era moderna deixam a esfera nacional para se transformar em uma guerra mundial contra o capitalismo ubíquo,

\footnotetext{
${ }^{9}$ Como curiosidade, cabe mencionar que o programa do Movimento declara que sua formulação se orienta segundo o programa “dos nossos amigos brasileiros do MLB”. (111)
} 
almejando a eliminação absoluta do inimigo, no qual se identifica a fonte de toda miséria humana. Esse passo cria a polarização absoluta entre os adversários e permite, virtualmente, a recorrência a todos os meios em ambos lados. Quem chega à conclusão de que o estado é o inimigo - seja por engano ou de maneira fundamentada -, coloca-se a si mesmo num dos pólos desse antagonismo irreconciliável e obriga seu oposto, queira ou não, a ocupar o outro pólo e servir-se dos mesmos meios absolutos. Essa é a armadilha que enfrentam os estados democráticos atualmente diante de uma nova forma de terrorismo, não menos radical e fanático que aquele dos anos 1970.

Voltando à autobiografia de Inge Viett, observamos que ela reclama justamente esse direito de combater um sistema pernicioso. Além da sua interpretação da situação política, é, sobretudo, um sentimento básico e forte que justifica e sustenta seu antagonismo em relação ao estado: negativamente a “ausência de angústia”, positivamente “o orgulho” de sentir a própria importância nas ações violentas (84s.). Na ilegalidade ela se sente livre da lógica do Imperialismo.

Eu estava do lado de fora, eu era algo novo, próprio. Nunca na minha vida estive mais segura e mais intrépida que nesses tempos no underground, o lugar em que nascia um outro ser fora do feio mundo. Nunca estive mais livre, nunca mais ligada à minha própria responsabilidade que nesse estado de completo desligamento da autoridade estatal e dos preceitos sociais. Nenhuma lei, nenhuma força externa determinava mais minha relação com o mundo, com a vida, com a morte. $(114 \mathrm{~s} \text {. })^{10}$

Esse sentimento de autonomia e poder dá título ao livro e, como parece, é um dos motivos mais fortes a manter Viett ainda fiel a esse passado. Aparentemente, a autora quer destacar o paradoxo: sua intrepidez chega ao auge quando é perseguida pelas forças unidas de um estado (e a maioria da população), ou seja, no momento de sua maior ameaça. A intensidade dos sentimentos de autonomia e de coragem lhe servem de indicadores para que esse estado de oposição absoluta seja o estado verdadeiro. Contudo, é necessário constatar que esse sentimento de soberania resulta exatamente da abdicação do reconhecimento de todos que estão do outro lado da "linha

\footnotetext{
10 „Ich war draußen, ich war etwas Neues, Eigenes. Nie in meinem Leben war ich sicherer und furchtloser als in dieser Zeit im Untergrund, dem Ort, der ein neues, anderes Sein außerhalb der häßlichen Welt gestattete. Nie war ich freier, nie war ich gebundener an meine eigene Verantwortung als in dem Zustand völliger Abnabelung von der staatlichen Autorität und von gesellschaftlichen Vorgaben. Kein Gesetz, keine äußere Gewalt bestimmte mehr mein Verhältnis zur Welt, zum Leben zum Tod.“
} 
clara que [os] separa do inimigo"11. Estar "ligada à sua própria responsabilidade” em vez de estar ligada a autoridades e preceitos sociais significa exatamente decidir sobre a vida e a morte daqueles que se encontram do outro lado da linha. A intensidade do sentimento se deve, em vez de ser um indicador da "vida verdadeira”, ao poder sobre seres humanos e a ilusão que esse poder seja controlado por uma moralidade superior: essa moralidade não tem fundamento no respeito do outro, mas na exclusão arbitrária de grupos determinados - um mecanismo bem conhecido da Revolução Francesa, dos massacres Stalinistas e do Nazismo. ${ }^{12}$

Parece estranho que a autora nem sequer na distância reflexiva da sua cela perceba que a luta armada não realiza a liberdade da "lógica destrutiva do sistema capitalista”; na realidade, essa luta apresenta todos os supostos vícios do sistema combatido. Se o estado - sempre segundo a opinião do grupo - rouba, eles começam roubando bancos, se o estado priva a liberdade individual, eles privam suas vítimas completamente de toda liberdade, se o estado destrói estruturas civilizadas, eles explodem os mesmos com suas bombas e matam pessoas com suas armas automáticas. A suposta liberação da violência consiste em aplicar exatamente os meios condenados, agora sem qualquer freio e moderação que limite o exercício do poder pelos órgãos legítimos no estado de direito. O sentimento tão festejado é o de gozo do poder sobre a vida alheia, mesmo que com este se misture a tensão do perigo de ser preso a qualquer momento. Muito longe de formar algo novo, próprio e diferente, os terroristas se convertem em uma réplica paródica do poder combatido. Se tivessem a sorte de vencer, estabeleceriam uma nova estrutura de opressão - mais violenta e cínica que a vencida, fenômeno tão familiar às revoluções históricas.

O sentimento de intrepidez, não obstante, deve servir de testemunho à autenticidade existencial da opção pela violência. O fracasso é atribuído, pela autora, a um encadeamento de fatores desfavoráveis fora do controle dos insurgentes: as massas da Europa Central são corrompidas por seu relativo bem-estar, o momento histórico não está maduro, a vontade aniquiladora do estado é subestimada.

\footnotetext{
${ }^{11}$ Citação de Mao Tse-tung; cf. "Das Konzept Stadtguerrilla” de abril 1971, o primeiro manifesto da RAF que desenvolve a argumentaçaõ geral da luta armada nas metropoles em solidariedade com as lutas no terceiro mundo. Rote Armee Fraktion 1997: 27-48; 44.

12 Sintomático parece também o uso de expressões como "Schweine" (porcos) para referir-se às pessoas que merecem ser eliminadas. Ibid.
} 
Como é que a autobiógrafa se lembra dos seres humanos vitimados em sua luta contra o sistema? Em primeiro lugar, ela considera todas as ações violentas da guerrilha como uma reação às vítimas surgidas entre os jovens mortos por órgãos do estado. $\mathrm{O}$ próprio nome do movimento rememora a data da morte de Benno Ohnesorg, estudante alvejado por um policial durante uma manifestação. A primeira bomba do grupo tem por alvo o cassino dos oficiais britânicos em Berlim e pretende ser uma 'resposta' ao “Domingo sangrento" de Londonderry. Devido a um engano, a bomba foi colocada na entrada do Yate-Clube existente ao lado, onde um construtor de barcos a encontrou e morreu quando tentava analisar o objeto. A primeira consideração da autora sobre o assunto refere-se à possibilidade de que o integrante do grupo que plantou a bomba talvez fosse um agente da polícia secreta, a qual, portanto, seria a responsável pela morte do inocente. Inge Viett não faz comentários sobre suas emoções no tempo da narração, somente sobre os sentimentos daquela época.

A morte do construtor de barcos não podia nos deter. Eu estava consternada, sim. Mas eu não me sentia responsável. $\mathrm{O}$ assunto me tocou mais como quando alguém se sente tocado pelo fato de um de seus conhecidos tivesse provocado um acidente fatal. $(91)^{13}$

Ainda que o grupo tomasse decisões e agisse de forma coletiva, ela se exime da culpa por meio de três operações: primeiro, não se tratou de um assassinato intencional, mas de um acidente; segundo, não foi ela (que plantou a bomba), mas um dos outros; e terceiro, esse talvez tivesse sido um agente infiltrado. De forma semelhante, embora muito mais cínica, ela imputa à polícia secreta a responsabilidade pelo assassinato de um outro integrante do grupo. É provável, no entanto, que este tenha sido 'executado' pelo grupo por ter colaborado com a polícia. A autobiógrafa narra o acontecimento assim: „Ele morreu evidentemente de uma bala / bola, com a qual os policiais tinham jogado bilhar e que havia saído da mesa e do controle deles.”14 (93)

O assassinato de um juiz da corte constitucional de Berlim é, de novo, uma 'resposta' à morte de um guerrilheiro na prisão (durante uma greve de fome). Para ela, as autoridades do Poder Judiciário e da prisão o deixaram morrer de fome. “A última foto dele mostra um homem morto emagrecido até o esqueleto. Em Buchenwald,

\footnotetext{
13 „Der Tod des Bootsbauers [...] konnte uns nicht aufhalten. Ich war bestürzt, ja. Aber ich fühlte mich nicht verantwortlich. Es berührte mich eher in der Weise, wie es einen Menschen berührt, in dessen Bekanntenkreis jemand einen tödlichen Unfall verursacht hat.“(91)

14 "Er starb offensichtlich an einer Kugel, mit der die sogenannten Verfassungsschützer Billard gespielt hatten und die ihnen dann vom Tisch gerollt war.“ (93)
} 
Galle, H. - A volta da violência na política alemã

Auschwitz, Ravensbrück, Sachsenhausen e em outros campos de concentração, os mortos tinham essa aparência.“15 (125) Mesmo que o emagrecimento do prisioneiro tenha sido conseqüência do seu próprio comportamento e da política dos líderes da RAF que intencionalmente levavam em consideração a morte de um dos grevistas, a autora insinua que ele fora vítima de um ato de violência parecido (ou idêntico) ao genocídio nazista. A autora afirma que o fato exerceu uma pressão no grupo para agir imediatamente, realizando um sequestro planejado, inicialmente, por outros motivos e que resulta, por ser precipitado e improvisado, em um assassinato em vez de sequestro. Ela não faz comentários a respeito de seus sentimentos atuais ou antigos, limitando-se a citar a declaração do grupo sobre a ação, declaração essa que começa da seguinte forma: “Quem semeia violência, colherá violência” (125). Embora o grupo “assuma a responsabilidade pela ação”, a autora imputa toda a culpa ao estado.

O acontecimento que, finalmente, representa o motivo pelo qual ela abandona a luta armada e se refugia na RDA ocorre quando ela atira num policial francês que a seguira de moto por Paris. Para ela, a culpa é da obstinação do homem, que a persegue sem considerar que "sua caça” poderia ser perigosa. Ela pega sua arma e manda que ele “desapareça”.

O olhar dele é incrédulo, idiota. Alguns segundos depois, ele avança lentamente para sua arma, interpretando de forma totalmente errônea a situação. Eu fito-o petrificada, ele fica cada vez menor, seu gesto lento em direção à pistola esfrega-se sobre meus olhos como uma sombra. Depois ocorre um tiro. Eu havia atirado. $(241)^{16}$

Para a autobiógrafa não se trata de um ato intencional, mas sim de "um acontecimento que ocorre sem vontade própria” e que, por isso, é “suprimido rapidamente e quase sem deixar vestígios” (241).

Apesar do meu envolvimento, a dinâmica de um acontecimento desse tipo não deixa lugar ou tempo para decisões autônomas. Por isso, a consciência recusa a responsabilidade por esse acontecimento. Recusa qualquer tipo de relação com ele. Durante todos esses anos eu não consegui sentir o mínimo pesar pelo policial alvejado. Ele não era uma pessoa concreta, nem sequer o inimigo concreto. Ele surgiu na minha vida em um momento somente como fatalidade, e essa fatalidade determinou-se pela situação provocada por ele, já que tal

\footnotetext{
15 „Das letzte Foto von ihm zeigt einen bis auf das Skelett abgemagerten toten Mann. In Buchenwald, Auschwitz, Ravensbrück, Sachsenhausen und den anderen KZs sahen die Toten so aus.“ (125)

16 „Ungläubig, dümmlich ist sein Blick. Sekundenlang, dann greift er langsam zu seiner Waffe in ungeheuerlicher Verkennung der Situation. Ich starre versteinert auf ihn, er wird kleiner und kleiner, seine langsame Bewegung zur Pistole wischt wie ein Schatten über meine Augen. Dann fällt der Schuss. Ich habe geschossen. “ (241)
} 
situação resultou das decisões dele. Se eu tivesse demorado um pouco mais para agir, a fatalidade poderia ter sido igualmente a minha. $(241 \mathrm{s.})^{17}$

De novo, ela não assume a responsabilidade pelo tiro que deixa o policial paralítico pelo resto da vida: A decisão foi dele, ela reagiu, forçada pelo encadeamento dos fatos. A ausência de emoções a respeito é descrita como um processo natural, como algo quase externo. Na sua narração, a “consciência” é uma instância com lógica própria, que “recusa a responsabilidade”, aparentemente sem que a pessoa tenha influência sobre ela. Nesse caso, a autora admite, pelo menos, que posteriormente, na ocasião do processo judicial - o disparo determinou sua condenação a 13 anos de prisão - sua vítima transformou-se “em uma pessoa de carne e sangue, com uma história de vida," que "foi condenada por ela a ficar para sempre em uma cadeira de rodas [...]. Só aí eu pude sentir profunda compaixão, porque permiti que me afetasse o futuro dele como homem paralítico e dependente.” (342) ${ }^{18}$

Resumindo, podemos dizer que a autobiógrafa busca reconstruir aquele horizonte dos anos 1970 no qual ela atuou e se sentiu como militante. O dominante sentimento de triunfo, a ausência de temor figurou como base da sua identidade e ela não quer abrir mão desse sentimento que somente poderia ser mantido como elemento positivo e correto se a visão de mundo que o produziu fosse também correta. Como consequência, ela relaciona essa visão com o fracassado projeto da RDA, ainda que, na realidade, tenha havido poucas pontes entre a ideologia oficial do socialismo real e as construções legitimadoras do terrorismo da esquerda.

Contudo, percebe-se no livro uma tentativa de justificar os atos violentos, execrados pela grande maioria da população e, finalmente, também pela parte nãomilitante do movimento estudantil. O livro é testemunho da tentativa da autora de

\footnotetext{
${ }^{17}$ „Obwohl selbst beteiligt, läßt die Dynamik eines solchen Geschehnisses keinen Platz und keine Zeit zu selbstbestimmten Entscheidungen. Darum verweigert das Bewußtsein auch die Verantwortung für dieses Geschehen. Verweigert überhaupt eine emotionale Beziehung dazu. Ich habe all die Jahre nicht das geringste Bedauern für den niedergeschossenen Polizisten empfinden können. Er war keine konkrete Person, nicht mal der konkrete Feind. Er ist nur einen Moment lang als Verhängnis in meinem Leben aufgetaucht, und dieses Verhängnis wurde von der Situation, die im Wesentlichen ein Ergebnis seiner Entscheidungen war, als seines bestimmt. Eine winzige Verschiebung im Ablauf und es hätte ebenso meines sein können." (241 s.)

18 „Erst zehn Jahre später, als ich mich auf diesen Prozeß wegen Mordversuchs vorbereitete und alle Ermittlungsakten studierte, wurde der Mann für mich zu einem realen Menschen, einer Person aus Fleisch und Blut mit einer Lebensgeschichte, die ihn dem kurzen Moment unseres Zusammentreffens durch mich zu einer Existenz im Rollstuhl verdammt worden ist und nun täglich das Leben neu erringen muß. Erst da konnte ich tiefes Mitleid fühlen, weil ich mir sein Schicksal als gelähmter und abhängiger Mensch nahekommen ließ. “ (242)
} 
assumir seus $\operatorname{atos}^{19}$ e de apresentá-los a um público que, por sua vez, não pode reconhecer a legitimidade de tais atos mas, pelo menos, compreendê-los dentro da lógica da sua biografia. Esse esforço da autora, no entanto, não pode ser bem-sucedido, na medida em que ela não consegue se desvincular do sentimento triunfal de sua identidade, já que o mesmo implica em não se arrepender por ter feito vítimas. Os leitores - particularmente as vítimas e seus familiares - dificilmente poderiam reconhecer (e perdoar) seus atos enquanto ela não assumir a plena responsabilidade por eles e enquanto sua identidade não for rompida.

A autobiografia mostra, por um lado, como essa pessoa chegou ao seu limite de autocompreensão e de compromisso com a sociedade. Por outro, a sociedade, no caso dessa ameaça à paz interna, não consegue se reconciliar com pessoas que não renunciam a suas atitudes anteriores e que não reconhecem inteiramente a integridade de suas vítimas. A perspectiva autobiográfica, neste caso, é demasiado particular e partidária para que seja integrada na memória coletiva. Ficcionalizando a biografia de Viett, o filme de Volker Schlöndorff apresenta uma versão mais objetiva dos acontecimentos que, embora seja inaceitável para ela, permite que a sociedade considere também a posição da terrorista dentro do contexto histórico e da experiência individual.

\section{Referências bibliográficas}

Aust, Stefan. Der Baader-Meinhof-Komplex. München: Knaur, 1989.

Honneth, Axel. Kampf um Anerkennung. Zur moralischen Grammatik sozialer Konflikte. Frankfurt a. M.: Suhrkamp, 2003.

Koenen, Gerd. Vesper, Ensslin, Baader. Urszenen des deutschen Terrorismus. Frankfurt a. M.: Fischer, 2005.

KraUSHAAR, Wolfgang, ed. Die RAF und der linke Terrorismus. 2 vols. Hamburg: Hamburger Edition, 2006.

Peters, Butz. Tödlicher Irrtum. Die Geschichte der RAF. Berlin: Argon, 2004.

RICEUn, Paul. Wege der Anerkennung. Erkennen, Wiedererkennen, Anerkennen. (Trad.) Ulrike Bokelmann and Barbara Heber-Schärer. Frankfurt a. M.: Suhrkamp, 2006. (Em português: Percurso do reconhecimento, Loyola, 2006.)

19 Nota-se, porém, que ela unicamente admite ter praticado os atos pelos quais foi efetivamente condenada na Justiça. Nos outros casos, ela mantém um véu sobre a responsabilidade individual de cada um dos membros do grupo. 
Rote Armee Fraktion. Texte und Materialien zu Geschichte der RAF. Berlin: ID-Verlag, 1997.

SchmitT, Carl. Theorie des Partisanen. Zwischenbemerkung zum Begriff des Politischen. Berlin: Duncker und Humblot, 2002.

StAROBInSKI, Jean. "Der Stil der Autobiographie." In: Die Autobiographie, (Ed.) Günter Niggl. Darmstadt: Wissenschaftliche Buchgesellschaft, 1998, 200-213.

THEWELEIT, Klaus: Ghosts. Drei leicht inkorrekte Vorträge. Frankfurt a.M.: Stroemfeld 1998.

VIETT, Inge: Nie war ich furchtloser. Autobiographie. Hamburg: Nautilus 1996. 